\title{
COVID-19 pneumonia with ARDS and secondary haemophagocytic lymphohistiocytosis: a case report
}

\author{
Hasan Ölmez ${ }^{1}$, Mustafa Tosun ${ }^{1}$, Edhem Ünver ${ }^{1} \oplus$, Nurten Arslan Işık²® \\ ${ }^{1}$ Department of Pulmonary Diseases, Erzincan Binali Yıldırım University Faculty of Medicine, Erzincan, Turkey \\ ${ }^{2}$ Department of Child Development, Erzincan Binali Yıldırım University Faculty of Health Sciences, Erzincan, Turkey
}

\begin{abstract}
Although most people with COVID-19 have mild to moderate symptoms; some people may experience worsened symptoms, such as pneumonia, acute respiratory distress syndrome (ARDS) and and respiratory failure. Here we reported a case of COVID-19 pneumonia with ARDS and secondary haemophagocytic lymphohistiocytosis (sHLH). A 44-year-old man presented to the emergency department with a history of cough, fever, sore throat, and muscle ache. The patient transferred to Chest Diseases Department, with a diagnosis of COVID-19 pneumonia. Oseltamivir, hydroxychloroquine, azithromycin, low molecular weight heparin (LMWH) and favipravir added to the treatment. Tocilizumab started after endotracheal intubation. In general, we saw improvement in respiratory values and vital signs. Administration of LMWH to the patient may have prevented the development of coagulopathy. In conclusion, using HFO system and using low tidal volume according to ARDS net protocol, using optimal PEEP/FiO2 ratio, paying attention to keeping driver pressures low may be beneficial for the clinical improvement of the disease.

Keywords: COVID-19, respiratory failure, pneumonia, ARDS, tocilizumab
\end{abstract}

C OVID-19 is the infectious disease caused by the most recently discovered coronavirus. This new virus and disease were unknown before the outbreak began in Wuhan, China, in December 2019. COVID19 is now a pandemic affecting many countries globally. The most common symptoms of COVID-19 are fever, dry cough, and tiredness. Some people become infected but only have very mild symptoms. Most people (about $80 \%$ ) recover from the disease without needing hospital treatment. Around 1 out of every 5 people who gets COVID-19 becomes seriously ill and develops difficulty breathing [1].

\section{CASE PRESENTATION}

A 44-year-old man presented to the emergency de- partment with a history of cough, fever, sore throat, and muscle ache. He had no history of use medications, smoking and alcohol. On physical examination, no abnormalities were found. Clinical examination revealed a temperature of $38^{\circ} \mathrm{C}$, a pulse rate of 112 beats per minute, a blood pressure of 120/80 mm Hg. He had rare inspiratory rales in the basal lungs. No feature was detected in other system examinations. Laboratory results were as follows: white blood count count (WBC) of $6.8 \mathrm{~L} \times 103 / \mathrm{uL}$ (normal 5.2-12.4 L×103/uL), a hemoglobin $(\mathrm{Hgb})$ of $13.8 \mathrm{~g} / \mathrm{dL}$ (normal: 12-18 $\mathrm{g} / \mathrm{dL}$ ) and a platelet count of $240 \times 103 / \mathrm{uL}$ (normal: $130-400 \times 103 / \mathrm{uL})$, C-reactive protein of $19.4 \mathrm{mg} / \mathrm{dL}$ (normal: 0.5-0.9 mg/dl), ferritin 518 (normal 12-300 $\mathrm{ng} / \mathrm{mL}$ ), D-dimer of $631 \mu \mathrm{g} / \mathrm{L}$, INR of 0.96 (normal: 0.8 to 1.1 ) and procalcitonin of $<0.12 \mathrm{ng} / \mathrm{ml}$ (normal: $0.00-0.05 \mathrm{ng} / \mathrm{ml})$. 
There was more peripheral density increase in the left lung lower zone on chest radiograph (Fig. 1). There were multiple ground-glass areas in the thorax CT, mostly in both lower lobes and peripheral regions (Fig. 2). The patient transferred to Chest Diseases Department, with a diagnosis of COVID-19 pneumonia. Hydroxychloroquine $2 \times 400 \mathrm{mg}$ (bolus), azithromycin $1 \times 500$ (bolus), influenza pneumonia, oseltamivir $2 \times 75$ mg and LMWH treatment at prophylactic dose were administered to the patient. The PCR sample taken from the patient twice; although the first was negative, the second test was evaluated as positive. On the 5th day of hospitalization, the general condition deteriorated and the patient's $\mathrm{SpO}_{2}$ decreased to $83 \%$ despite $3 \mathrm{~L} /$ minute oxygen inhalation by face mask. The leukocyte, platelet, ferritin, D-dimer, CRP and INR values were increased, and the lymphocyte and hemoglobin values were decreased (Table 1). The patient's control chest x-ray showed an increase in heterogeneous density in both middle and lower zones of the lung. We observed worsening in the first radiograph compared to the other (Fig. 3). The patient was taken to the intensive care unit because of the his current findings, and favipravir $2 \times 1600 \mathrm{mg}$ (bolus) and piperacilin-tazobactam $3 \times 4.5 \mathrm{~g}$ and levofloxacin $1 \times 750 \mathrm{mg}$ were added to his current treatment. As the patient's oxygen saturation was low, high flow oxygen therapy (HFO) was started (40 L/ min flow and FIO2 $100 \%$ ). On day 10 of hospitalization the patient was intubated and connected to the mechanical ventilator (Table 2) (Fig. 4) (respiratory rate of 42 breaths per minute, oxygen saturation of $80 \%$, increased leukocyte, D-dimer, ferritin, CRP and procalcitonin values, worsening arterial blood gas values and worsening on chest x-ray).

The patient's syptoms were moderately compatible with ARDS (PEEP / Fi02 = 123). Therefore, MV was applied to the patient with low tidal volume (4-6 $\mathrm{ml} / \mathrm{kg}$ ), low plateau pressure $(<30 \mathrm{~cm} \mathrm{H} 2 \mathrm{O})$, low drive pressure $(<15 \mathrm{~cm} \mathrm{H2O})$ and optimal PEEP/Fi02 values in accordance with the ARDS net protocol. The patient was started to be followed up in VC-SIMV mode with a dose of $0.02-01 \mathrm{mg} / \mathrm{kg} / \mathrm{h}$ with midazolam (Table 3). As the patient's clinical and laboratory values were compatible with secured hemophagocytic lymphohistiocytosis (sHLH), tosilizumab (400 $\mathrm{mg}+400 \mathrm{mg}$ ) treatment was started in addition to the current treatment. On the 15 th day of hospitalization (on the 5th day of intubation) respiratory values (Table 2) and laboratory values (Table 1) of the patient improved. Regression was observed on the chest X-ray of the patient (Fig. 5). Upon improvement in the general condition of the patient, his sedation was reduced and discontinued. The patient was extubated according

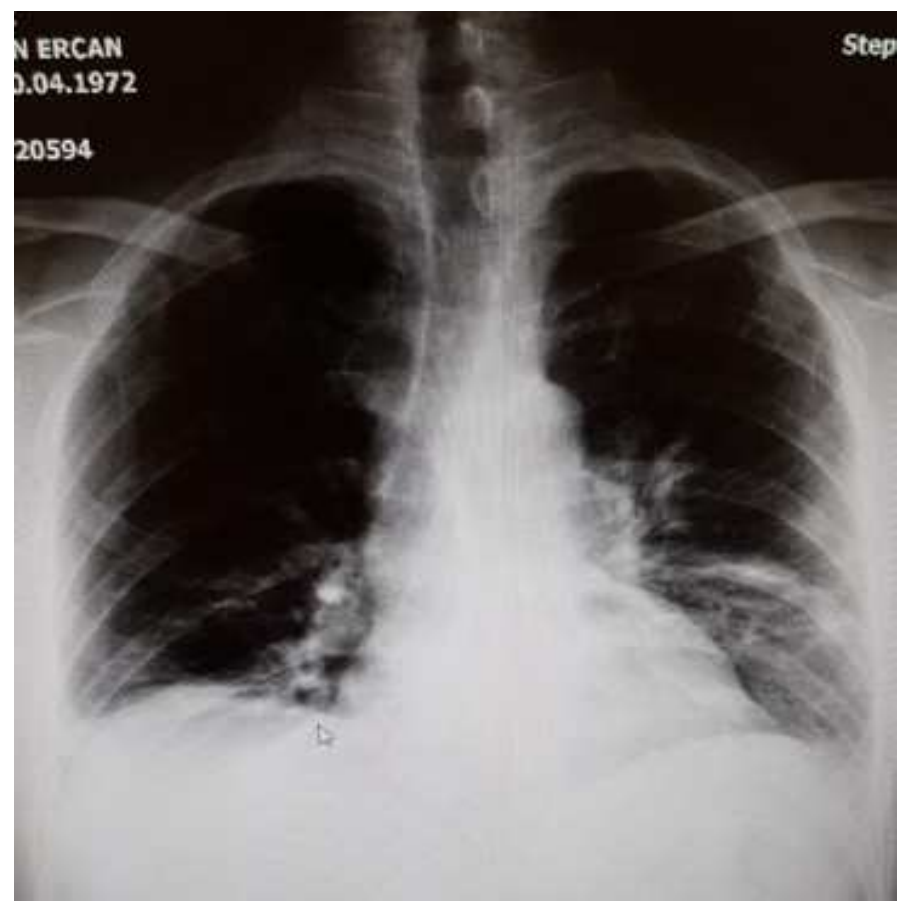

Fig. 1. Hospitalization Chest X-ray

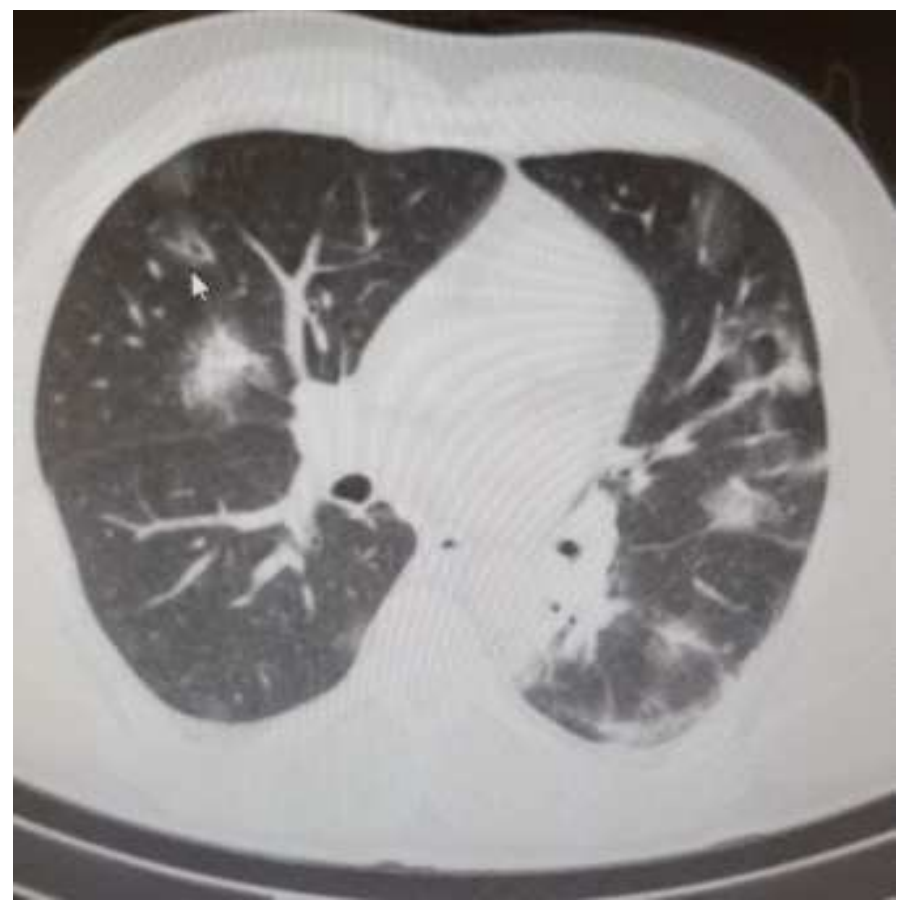

Fig. 2. a-Hospitalization thorax CT. 
Table 1. Laboratory results of the patient

\begin{tabular}{|c|c|c|c|c|c|c|}
\hline Parameters & $\begin{array}{c}\text { Day } 1 \\
\text { (hospitalization) }\end{array}$ & $\begin{array}{l}\text { Day } 5 \\
\text { (HFO) }\end{array}$ & $\begin{array}{l}\text { Day } 10 \\
\text { (IMV) }\end{array}$ & $\begin{array}{l}\text { Day } 13 \\
\text { (IMV) }\end{array}$ & $\begin{array}{l}\text { Day } 17 \\
\text { (O2) }\end{array}$ & $\begin{array}{l}\text { Day } 20 \\
\text { (Room) }\end{array}$ \\
\hline Leukocyte* $\left(\times 10^{3} / \mu \mathrm{L}\right)$ & 6800 & 13000 & 15800 & 7000 & 7200 & 8100 \\
\hline $\begin{array}{l}\text { Lymphocytet } \#\left(\times 10^{-3} /\right. \\
\mu \mathrm{L})\end{array}$ & 2 & 1 & 0.59 & 0.71 & 1.86 & 2.68 \\
\hline $\mathrm{Hb} \#(\mathrm{~g} / \mathrm{dL})$ & 13.8 & 11.8 & 9.6 & 8,3 & 10,3 & 11.2 \\
\hline Platelets & 240000 & 350000 & 546000 & 377000 & 354000 & 283000 \\
\hline Ferritin* & 518 & 673 & 710 & 612 & 654 & 733 \\
\hline Fibrinogen\# (mg/dL) & 417 & 398 & 372 & 358 & 276 & 209 \\
\hline D-dimer* $(\mu \mathrm{g} / \mathrm{L})$ & 631 & 1090 & 6390 & 2430 & 1867 & 443 \\
\hline Troponin (ng/L) & $<10$ & $<10$ & $<10$ & $<10$ & $<10$ & $<10$ \\
\hline INR* & 0.96 & 1.12 & 1.7 & 1,8 & 1.4 & 0.99 \\
\hline $\mathrm{CRP}^{*}(\mathrm{mg} / \mathrm{L})$ & 19.4 & 144 & 171 & 25 & 12 & $<3$ \\
\hline Procalcitonin* (ng/ml) & $<0.12$ & 0.8 & 1.3 & 0.32 & $<0.12$ & $<0.12$ \\
\hline $\operatorname{ALT}(\mathrm{u} / \mathrm{L})$ & 26 & 58 & 46 & 82 & 105 & 129 \\
\hline $\operatorname{AST}(\mathrm{u} / \mathrm{L})$ & 30 & 33 & 44 & 58 & 83 & 55 \\
\hline $\mathrm{CK}(\mathrm{u} / \mathrm{L})$ & 134 & 128 & 136 & 140 & 142 & 143 \\
\hline $\mathrm{LDH} \mathrm{u/L}$ & 278 & 329 & 341 & 422 & 310 & 258 \\
\hline Triglyceride (mg/dL) & 256 & 260 & 302 & 384 & 414 & 551 \\
\hline
\end{tabular}

The parameters marked $*$ showed a positive correlation with the progression of the disease, and a positive correlation with the \# marked parameter.

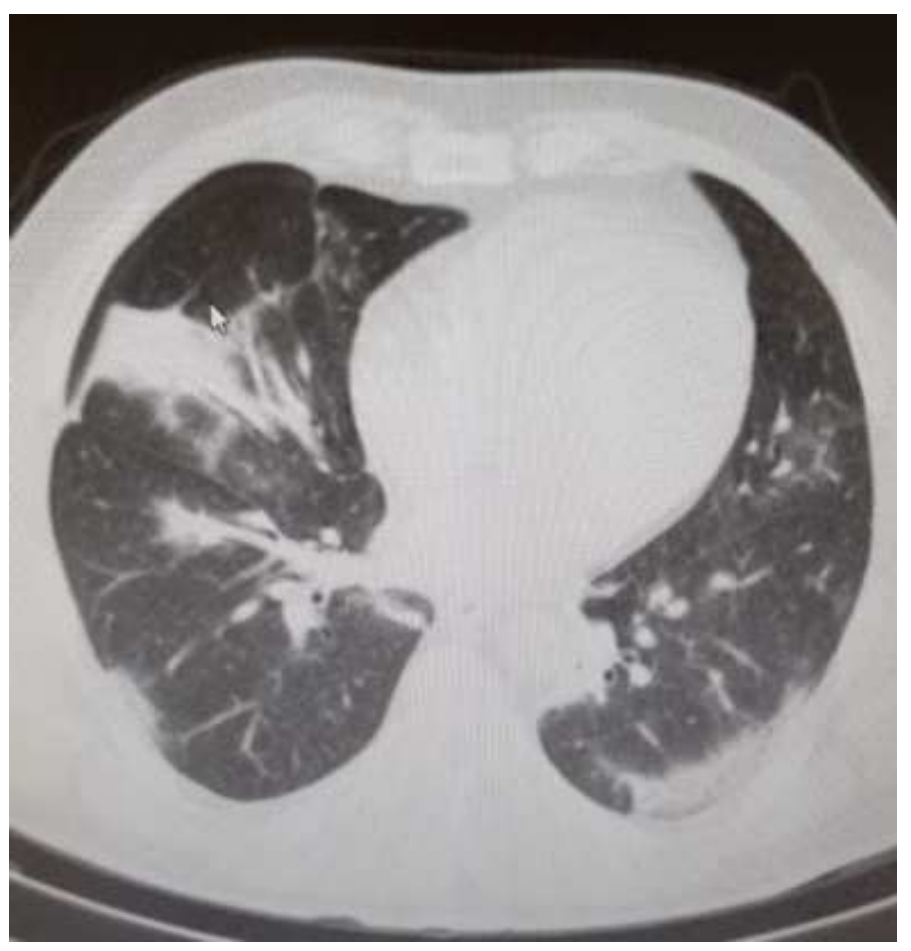

Fig. 2. b-Hospitalization thorax CT.

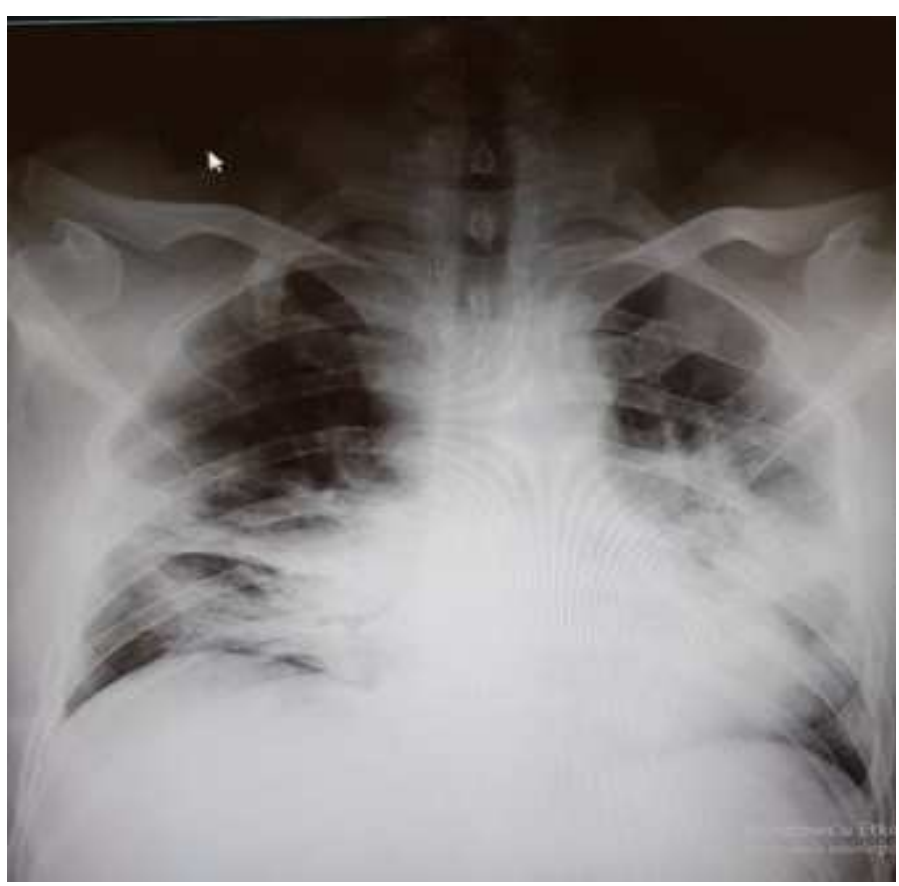

Fig. 3. Intensive care hospitalized chest X-ray (Day 5 of hospitalization). 
to the weaning protocol on the 17 th day of hospitalization and 7 days after intubation. The patient was transferred to the chest service. Patients' laboratory values (Table 1) and chest X-ray result found normal (Fig. 6). The patient was discharged with a prophylactic dose of LMWH.

\section{DISCUSSION}

The vast majority of COVID-19 patients presented with lymphocytopenia (83.2\%), whereas $36.2 \%$ had thrombocytopenia, and $33.7 \%$ showed leukopenia, increased values of CRP (75-93\% of cases), LDH (2$92 \%$ of cases), ESR (up to $85 \%$ of cases) and D-dimer

Table 2. Respiratory values of the patient

\begin{tabular}{lcccccc}
\hline Parameters & $\begin{array}{c}\text { Day 1 } \\
\text { (hospitalization) }\end{array}$ & $\begin{array}{c}\text { Day 5 } \\
\text { (HFO) }\end{array}$ & $\begin{array}{c}\text { Day 10 } \\
\text { (IMV) }\end{array}$ & $\begin{array}{c}\text { Day 13 } \\
\text { (IMV) }\end{array}$ & Day 17 (O2) & $\begin{array}{c}\text { Day 20 } \\
\text { (Room) }\end{array}$ \\
\hline $\begin{array}{l}\text { Respiratory rate } \\
\text { (Lt / min) }\end{array}$ & 18 & 28 & 42 & 20 & 19 & 16 \\
PH & & & & & & \\
PCO2 (mmHg) & & 7.49 & 7.37 & 7.48 & 7.46 & \\
PO2 (mmHg) & & 30 & 60.2 & 38 & 39 & \\
HCO3 (mEq/L) & & 96 & 74 & 63,8 & 67 & \\
O2 sat (\%) & 25 & 31 & 29 & 28 & \\
Lactate (mmol/L) & & 97 & 80 & 91 & 95 & 97 \\
PaO2/FiO2 & & 1.4 & 2.1 & 1.2 & 1.1 & \\
FiO2 (\%) & 118 & 123 & 116 & 167 & 320 \\
\hline
\end{tabular}

Table 3. Monitored values in patient's ventilator follow-up

\begin{tabular}{|c|c|c|c|}
\hline & $\begin{array}{l}\text { Day } 10 \\
\text { (IMV) }\end{array}$ & $\begin{array}{l}\text { Day } 13 \\
\text { (IMV) }\end{array}$ & $\begin{array}{c}\text { Day } 17 \\
\text { (O2) }\end{array}$ \\
\hline MODE & VC-SIMV & VC-SIMV & VC-SIMV \\
\hline FiO2 & 60 & 55 & 40 \\
\hline $\mathrm{PaO} 2 / \mathrm{FiO} 2$ & 123 & 116 & 167 \\
\hline VT & 400 & 400 & 400 \\
\hline $\mathrm{T}$ isn & 1.5 & 1.5 & 1.5 \\
\hline PEEP (cmH20) & 15 & 12 & 5 \\
\hline Support Pressure (cmH20) & 20 & 18 & 10 \\
\hline Insp, flow (L/min) & 45 & 50 & 45 \\
\hline $\operatorname{MVE}(\mathrm{L} / \mathrm{min})$ & 12.3 & 8.9 & 7.3 \\
\hline VTE (ml) & 420 & 370 & 372 \\
\hline RR & 18 & 18 & 18 \\
\hline TOTAL RR & 22 & 20 & 19 \\
\hline Plateau Pressure $(\mathrm{cmH} 20)$ & 27 & 24 & 16 \\
\hline Drive Pressure $(\mathrm{cmH} 20)$ & 12 & 12 & 11 \\
\hline Resistance & 16.4 & 10 & 8.4 \\
\hline Dynamic Compliance $(\mathrm{mL} / \mathrm{cmH} 2 \mathrm{O})$ & 70 & 94 & 103 \\
\hline
\end{tabular}




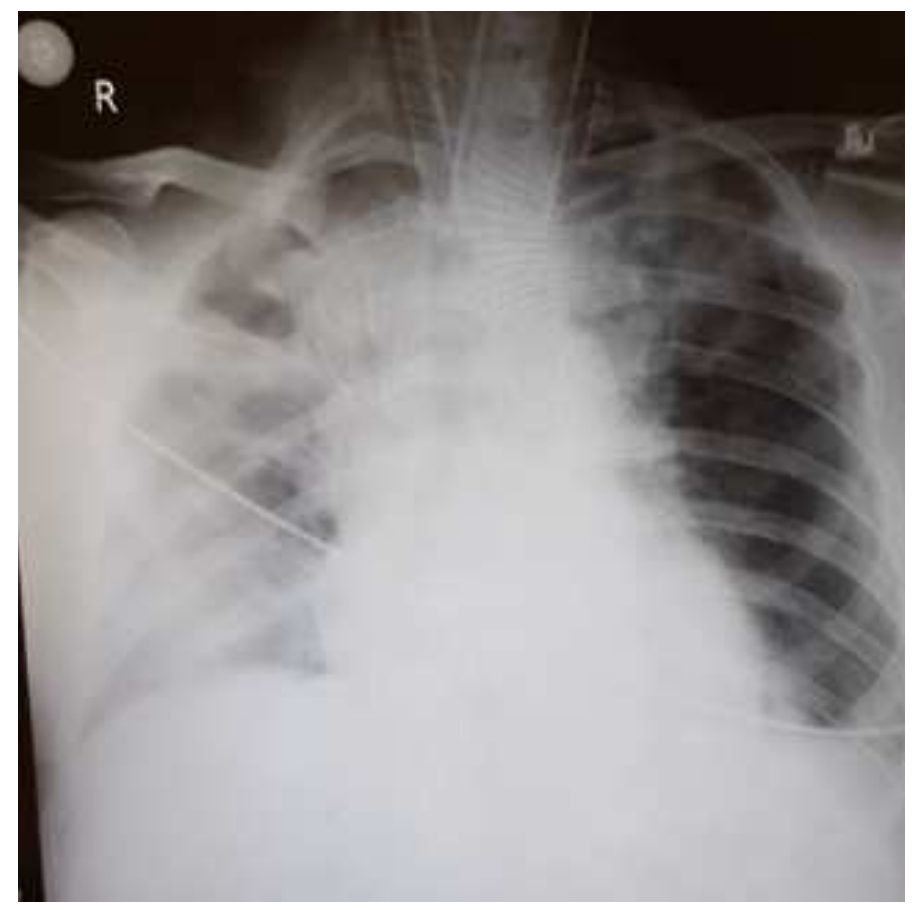

Fig. 5. Chest $x$-ray (transferred from the intensive care unit to the service-Day 17 of hospitalization).

(36-43\% of cases), as well as low concentrations of serum albumin (50-98\% of cases) and hemoglobin (41-50\%) [6-8]. Increased white blood cell count, increased neutrophil count, decreased lymphocyte count, decreased albumin, increased LDH, ALT, AST, bilirubin, creatinine, cardiac troponins, D-dimer, prothrombin time, procalcitonin and CRP values. In our case, leukocyte, CRP, procalcitonin, ferritin, INR, triglyceride, D-Dimer values increased as disease progression increased. The lymphocyte count and hemoglobin values of the patient decreased as the disease progressed (Table 1). In our case, AST, ALT, LDH, $\mathrm{CK}$, fibrinogen, platelet values did not correlate with the patient's progression. In addition, the patient's increased triglyceride values did not reach normal values despite the patient's clinical and radiological regression. During hospitalization, a nasopharyngeal swab was taken 2 times with an interval of 48 hours, and a real-time PCR test was performed, but a negative result was found. The first rapid antibody test on the 5th day of hospitalization was negative. The second rapid antibody test was found positive. It is known that viral load is high in nasopharyngeal secretions during the first week. In a study, $63 \%$ of nasal swabs and $32 \%$ of pharyngeal swabs were detected [9]. However, in real time PCR tests, many factors such as sample sample

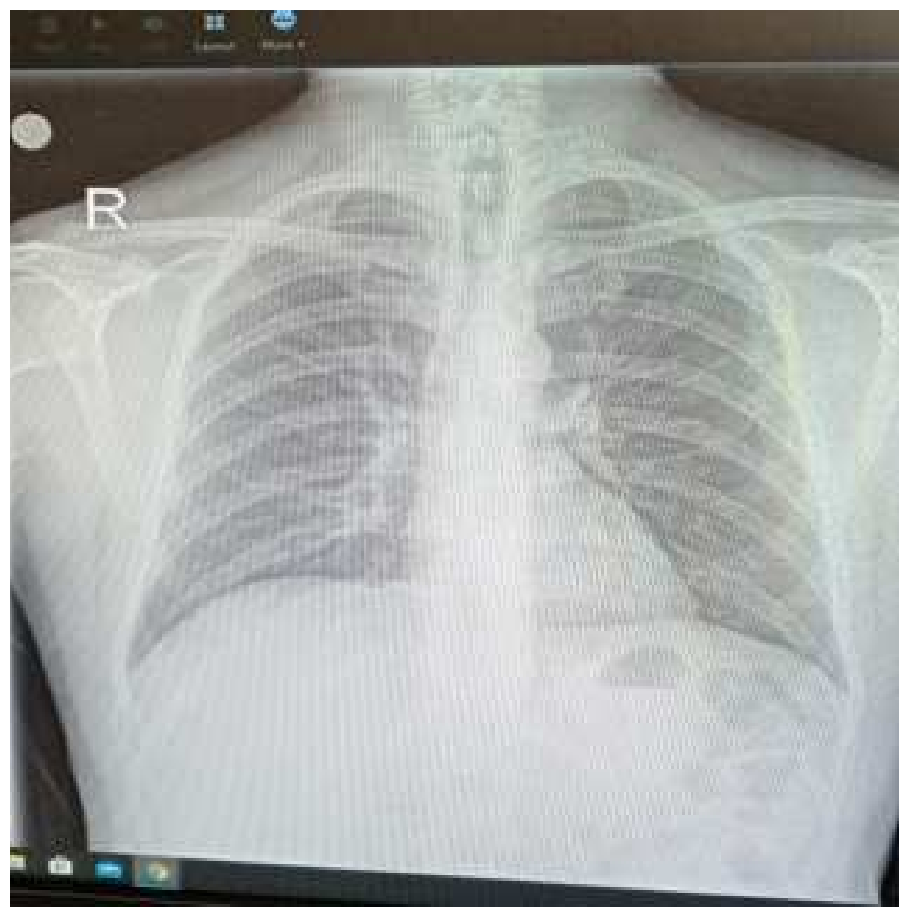

Fig. 6. Chest X-ray, Discharged (Day 20 of hospitalization)

quality, collection time of clinical samples, and transfer in unfavorable conditions affect the test results. Rapid antibody testing may be negative when performed at an early stage. Positivity rates are maximum 5-14 days after symptoms begin. However, antibody formation may not be the same in every patient. Realtime PCR is the gold standard in the diagnosis of the disease. However, it may show false negativity in the early stage of the disease $[10,11]$. It should be borne in mind that in the early stage of the disease, limited frosted glass can not be seen on the chest radiograph. Sensitivity of chest radiography is reported between $30-60 \%$ [12]. In this case, chest x-ray showed an increase in heterogeneous density in the left lung lower zone with peripheral location (Fig. 1). However, this image is not specific for COVID-19 pneumonia. Therefore, our patient received a non-contrasted tho$\operatorname{rax} \mathrm{CT}$. In the thorax $\mathrm{CT}$, multiple frosted glass opacities were noted in all bilateral lung areas, mostly peripheral and in the lower lobe. In the studies conducted, the sensitivity of the real-time PCR test at the early stage of the disease was $71 \%$, and the sensitivity of Torak CT was 98\% [10,11] Consolidation, cobblestone view, air bronchogram, vascular enlargement, bronchial dilatation, halo sign, inverse halo sign, nodules, air bubble (air-bubble), subpleural and parenchy- 
mal bands were seen in cases of COVID-19 pneumonia in the literature [13-16]. Progression of consolidation and expansion to the upper lobes, development of pleural or pericardial fluid, development of lymphadenopathy, bronchiectasis, halo sign, cavitation development, and pneumothorax are poor prognostic factors. In our case, radiological progression was observed from the 5th day of hospitalization and the consolidation extended to both apical regions (Fig. 3 and 4). The majority of people infected with COVID-19 are asymptomatic, $14 \%$ of patients are hospitalized and $5 \%$ of them need intensive care [1]. Currently, there is no vaccine or antiviral treatment for COVID19. Current treatments are given to prevent the entry of the virus into the cell, reduce its replication and suppress the increased inflammatory response [17]. We applied hydroxychloroquine treatment to the patient since his hospitalization. Because studies have shown that hydroxychloroquine reduces binding of the virus to angiotensin-converting enzyme 2 (ACE2) receptor and reduces the spread of the virus [18]. In addition, it has been shown that chloroxine is effective in preventing the development of the patient's pneumonia, shortening the disease duration and PCR negation [19]. We started Oseltamivir treatment. Because it was determined that $4.3 \%$ of COVID- 19 patients can have influenza infection at the same time. However, differentiation of influenza pneumonia and COVID-19 pneumonia is not possible radiologically [20]. We started azithromycin as an initial treatment for our patient. Because it is known that macrolides have antiinflammatory properties such as down regulation and adhesion molecules inhibition, as well as antibacterial properties of proinflammatory cytokines [21]. Therefore, it is thought to be used in COVID-19 pneumonia [22]. Finally, we started a prophylactic dose of LMWH in our patient. Because in COVID-19 infection, there are studies showing that patients with high D-dimer values and severe pictures can be complicated by thrombosis and that such cases are mortal. In autopsy studies, vasculitis, small vessel occlusion, and thrombotic microangiopathy were observed in these patients [23-25]. LMWH treatment reduces the risk of mortality [26]. As a result, we started treatment with oseltamivir, hydroxychloroquine, azithromycin and LMWH. We added favipravir to the current treatment due to the clinical, laboratory and radiological progress monitoring of the patient. Because favipravir is a purine analogue with RNA-dependent RNA polymerase inhibitor (RBRI) and it can be effective in COVID-19 infection just as it is in SARS and MERS since it contains the SARCoV-2 virus RBRI [27]. However, despite the favipravir treatment given, our patient still showed progression. Chen et al. [28] have been reported that abnormal AST and ALT following treatment with favipiravir. We considered secondary hemophagocytic lymphohistiocytosis (sHLH) due to; worsening of breathing, moderate ARDS, continued radiological progression, decreased lymphocyte and hemoglobin values, increased ferritin, D-dimer, triglyceride level and we started to tosilizumab treatment. In studies conducted in China, secondary hemophagocytic lymphohistiocytosis (sHLH) similar picture was observed in COVID-19 patients [8]. This may be due to the fact that the virus activates CD4 + T lymphocytes after entry into the cell, leading to the formation of $\mathrm{T}$ hepler (Th), and the activation of inflammatory cytokines by activating the release of IL6 from monocytes and macrophages through GM-CSF and other inflammatory cytokines (17). Since our patient had bilateral lung infiltration in the last week and $\mathrm{PaO}_{2} / \mathrm{FiO}_{2}$ ratio was 123 , we accepted it as medium ARDS according to Berlin definition [29]. Our patient had bilateral lung infiltration in the last week and $\mathrm{PaO} 2 / \mathrm{FiO} 2$ ratio was 123 , and we accepted our patient as middle ARDS according to Berlin definition [29]. We used a volume-controlled mode for our patient. We used the low tidal volume $(6 \mathrm{ml} / \mathrm{kg})$, optimal $\mathrm{PEEP} / \mathrm{FiO} 2$ ratio according to the ARDS network table. We tried to comply with the targets of plateau pressure $\left(\right.$ PPLAT) $<30 \mathrm{cmH} 20, \mathrm{pH}>7.30, \mathrm{pO}_{2}>60$ $\mathrm{mmHg}$ and $\mathrm{spO}_{2}>90$. Studies show that compliance and shunt fraction may differ from ARDS in patients who develop and intubate with COVID-19 pneumonia. Thorax CT findings of different severity were observed in patients with the same $\mathrm{PaO}_{2} / \mathrm{FiO}_{2}$ ratio. Symptom onset and radiological involvement of patients may not be compatible with ARDS in all cases. Therefore, it may be beneficial to continue patients with HFO as much as possible without intubation. Gattinoni et al. [30, 31] (Explained hypoxia in 3 different mechanisms in patients with COVID-19 pneumonia.) These are dysregulation in pulmonary perfusion, microtrombus in lung parenchyma, noncardiogenic pulmonary edema. For this reason, they divided the patients into two groups, $\mathrm{H}$ and $\mathrm{L}$ feno- 
type. The main problem in the L phenotype is perfusion dysregulation and microthrombus. Therefore, patients with this phenotype do not respond to high PEEP, recruitment therapy and pron position. In patients with $\mathrm{H}$ phenotype, elastance was high and compliance was low. Therefore, high PEEP can respond to recruitment therapy and pron position. Patients can switch from the L phenotype to the $\mathrm{H}$ phenotype [30, 31]. Considering the air resistance and dynamic compliance values in our case, it fits the L phenotype. Therefore, high PEEP, recruitment therapy, prone position and neuromuscular blockade were not required.

\section{CONCLUSION}

Approximately 14\% of confirmed cases developed severe disease, while the grand fatality rate was $4.2 \%$. No pharmaceutical products have yet been shown to be safe and effective for the treatment of COVID-19. Current treatments are provided to prevent the entry of the virus into the cell, reduce replication and suppress the increased inflammatory response. We gave our patient primarily oseltamivir, hydroxychloroquine, azithromycin, LMWH treatment. However, we added favipravir upon progression. Due to the suspicion of cytokine storm, we started early treatment of tocilizumab. In general condition, respiratory values and vital signs of our patient improved. We observed radiological regression in a short time. Administration of LMWH to the patient may have prevented the development of coagulopathy. Using HFO system and not rushing for intubation, using low tidal volume according to ARDSnet protocol, using optimal $\mathrm{PEEP} / \mathrm{FiO} 2$ ratio, paying attention to keeping driver pressures low may be beneficial for the clinical improvement of the disease.

Authors' Contribution

Study Conception: HÖ, MT, EÜ; Study Design: HÖ, MT, EÜ; Supervision: HÖ, MT, EÜ; Funding: HÖ, MT, EÜ; Materials: HÖ, MT, EÜ; Data Collection and/or Processing: HÖ, MT, EÜ; Statistical Analysis and/or Data Interpretation: HÖ, MT, EÜ; Literature Review: HÖ, MT, EÜ, NAİ; Manuscript Preparation: HÖ, MT, EÜ, NAİ and Critical Review: HÖ, MT, EÜ, NAİ.

\section{Informed consent}

Written informed consent was obtained from the patient for publication of this case and any accompanying images.

\section{Conflict of interest}

The authors disclosed no conflict of interest during the preparation or publication of this manuscript.

\section{Ethical approval}

This study was approved by the Ethics Committee of Erzincan University.

\section{REFERENCES}

1. WHO. Novel Coronavirus (2019-nCoV): situation report, 3 [Internet]. 2020 [cited 2020 May 3]. Available from: https://apps.who.int/iris/bitstream/handle/10665/330762/nCoVsitrep23Jan2020-eng.pdf

2. Guan WJ, Ni ZY, Hu Y, Liang WH, Ou CQ, He JX, et al. Clinical characteristics of coronavirus disease 2019 in China. N Engl J Med 2020;382:1708-20.

3. Wang Z, Yang B, Li Q, Wen L, Zhang R. Clinical features of 69 cases with coronavirus disease 2019 in Wuhan, China. Clin Infect Dis 2020;71:769-77.

4. Wang C, Horby PW, Hayden FG, Gao GF. A novel coronavirus outbreak of global health concern. Lancet 2020;395:470-3.

5. Wu Z, McGoogan JM. Characteristics of and important lessons from the coronavirus disease 2019 (COVID-19) outbreak in China: Summary of a Report of 72314 cases from the Chinese Center for Disease Control and Prevention. JAMA 2020;323:1239-42.

6. Wu C, Chen X, Cai Y, Xia J, Zhou X, Xu S, et al. Risk factors associated with acute respiratory distress syndrome and death in patients with coronavirus disease 2019 pneumonia in Wuhan, China. JAMA Intern Med 2020;180:934-43.

7. Zhou F, Yu T, Du R, Fan G, Liu Y, Liu Z, et al. Clinical course and risk factors for mortality of adult inpatients with COVID-19 in Wuhan, China: a retrospective cohort study. Lancet 2020;395:1054-62.

8. Huang C, Wang Y, Li X, Ren L, Zhao J, Hu Y, et al. Clinical features of patients infected with 2019 novel coronavirus in Wuhan, China. Lancet 2020;395:497-506.

9. Wang W, Xu Y, Gao R, Lu R, Han K, Wu G, et al. Detection of SARS-CoV-2 in different types of clinical specimens. JAMA 2020;323:1843-4.

10. Huang P, Liu T, Huang L, Liu H, Lei M, Xu W, et al. Use of chest CT in combination with negative RT-PCR assay for the 2019 novel coronavirus but high clinical suspicion. Radiology 2020;295:22-3.

11. Xie X, Zhong Z, Zhao W, Zheng C, Wang F, Liu J. Chest CT for typical 2019-nCoV pneumonia: relationship to negative RTPCR testing. Radiology 2020;296:E41-5.

12. Kong W, Agarwal PP. Chest imaging appearance of COVID19 infection. Radiol Cardiothorac Imaging 2020;2:e200028. 
13. Pan Y, Guan H. Imaging changes in patients with 2019-nCov. Eur Radiol 2020;30:3612-3.

14. Ye Z, Zhang Y, Wang Y, Huang Z, Song B. Chest CT manifestations of new coronavirus disease 2019 (COVID-19): a pictorial review. Eur Radiol 2020;30:4381-9.

15. Wu Y, Xie Y, Wang X. Longitudinal CT findings in COVID19 pneumonia: case presenting organizing pneumonia pattern. Radiol Cardiothorac Imaging 2020;2:e200031.

16. Li X, Zeng X, Liu B, Yu Y. COVID-19 infection presenting with CT halo sign. Radiol Cardiothorac Imaging 2020;2:e200026.

17. Zhou Y, Fu B, Zheng X, Wang D, Zhao C, Qi Y, et al. Pathogenic T-cells and inflammatory monocytes incite inflammatory storms in severe COVID-19 patients. Nat Sci Rev 2020;7:9981002 .

18. Vincent MJ, Bergeron E, Benjannet S, Erickson BR, Rollin PE, Ksiazek TG, et al. Chloroquine is a potent inhibitor of SARS coronavirus infection and spread. Virol J 2005;2:69.

19. Gao J, Tian Z, Yang X. Breakthrough: chloroquine phosphate has shown apparent efficacy in treatment of COVID-19 associated pneumonia in clinical studies. Biosci Trends 2020;14:72-3. 20. Ding Q, Lu P, Fan Y, Xia Y, Liu M. The clinical characteristics of pneumonia patients coinfected with 2019 novel coronavirus and influenza virus in Wuhan, China. J Med Virol 2020;92:15491555 .

21. Kanoh S, Rubin BK. Mechanisms of action and clinical application of macrolides as immunomodulatory medications. Clin Microbiol Rev 2010;23:590-615.

22. Tran DH, Sugamata R, Hirose T, Suzuli T, Noguchi Y, Sugawara A, et al. Azithromycin, a 15-membered macrolide antibiotic, inhibits influenza A (H1N1) pdm09 virus infection by interfering with virus internalization process. J Antibiot (Tokyo)
2019;72:759-68.

23. Levi M, van der Poll T. Coagulation and sepsis. Thromb Res 2017;149:38-44.

24. Gupta N, Zhao YY, Evans CE. The stimulation of thrombosis by hypoxia. Thromb Res 2019;181:77-83.

25. Luo WR, Yu H, Gou JZ, Li XX, Sun Y, Li JX, et al. Histopathologic findings in the explant lungs of a patient with COVID-19 treated with bilateral orthotopic lung transplant. Transplantation 2020;104:e329-31.

26. Tang N, Bai H, Chen X, Gong J, Li D, Sun Z. Anticoagulant treatment is associated with decreased mortality in severe coronavirus disease 2019 patients with coagulopathy. J Thromb Haemost 2020;18:1094-9.

27. De Clercq E. New nucleoside analogues for the treatment of hemorrhagic fever virus infections. Chem Asian J 2019;14:39628 .

28. Chen C, Zhang Y, Huang J, Yin P, Cheng Z, Wu J, et al. Favipiravir versus arbidol for COVID-19: a randomized clinical trial. medrxiv.org [Internet]. [cited 2020 May 4]; Available from: https://doi.org/10.1101/2020.03.17.20037432.

29. Ranieri VM, Rubenfeld GD, Thompson BT, Ferguson ND, Caldwell E, Fan E, et al. Acute respiratory distress syndrome: the Berlin definition. JAMA 2012;307:2526-33.

30. Gattinoni L, Coppola S, Cressoni M, Busana M, Rossi S, Chiumello D. Covid-19 does not lead to a "typical" acute respiratory distress syndrome. Am J Respir Crit Care Med 2020;201:1299300 .

31. Gattinoni L, Chiumello D, Caironi P, Busana M, Romitti F, Brazzi L, et al. COVID-19 pneumonia: different respiratory treatments for different phenotypes? Intensive Care Med 2020;46:1099-102. 